\title{
Long-term acclimation of anaerobic sludges for high-rate methanogenesis from LCFA
}

\author{
Sérgio A. Silva ${ }^{a}$, Ana J. Cavaleiro ${ }^{a}$, Maria Alcina Pereira ${ }^{a}$, \\ Alfons J.M. Stams ${ }^{a, b}$, Maria Madalena Alves ${ }^{a}$, Diana Z. Sousa ${ }^{a, b, *}$ \\ a Centre of Biological Engineering, University of Minho, Campus de Gualtar, 4710-057 Braga, Portugal \\ ${ }^{\mathrm{b}}$ Laboratory of Microbiology, Wageningen University, Dreijenplein 10, Buildingnumber 316, 6703 HB Wageningen, \\ The Netherlands
}

\section{A R T I C L E I N F O}

Article history:

Received 11 May 2014

Accepted 13 May 2014

Available online

Keywords:

High-rate methanogenesis

LCFA

Long term acclimation

Syntrophomonas zehnderi

Methanobacterium formicicum

\begin{abstract}
A B S T R A C T
Inhibition of methanogens by long chain fatty acids (LCFA) and the low numbers of LCFAdegrading bacteria are limitations to exploit biogas production from fat-rich wastewaters. Generally reactors fail due to excessive LCFA accumulation onto the sludge. Here, longterm acclimation and bioaugmentation with a LCFA-degrading coculture were hypothesized as strategies to enhance methanogenic conversion of these compounds. Anaerobic sludges previously exposed to LCFA for more than 100 days converted a specific biomassassociated substrate of $(3.2 \pm 0.1) \mathrm{kg} \cdot \mathrm{kg}^{-1}$ with very short lag phases ( $<1$ day), whereas nonacclimated sludges showed lag phases of 11-15 days for metabolizing (1.6-1.8) $\mathrm{kg} \cdot \mathrm{kg}^{-1}$. Addition of a coculture of Syntrophomonas zehnderi and Methanobacterium formicicum to sludges previously loaded with LCFA and containing different amounts of biomassassociated substrate (from $(0.5-3.2) \mathrm{kg} \cdot \mathrm{kg}^{-1}$ ) did not improve methane production neither lag phases were shortened, indicating that the endogenous microbiota are not a limiting factor. Clearly, we show that long-term sludge acclimation to LCFA is essential for high rate methanogenesis from LCFA.
\end{abstract}

(c) 2014 Elsevier Ltd. All rights reserved.

\section{Introduction}

Long chain fatty acids (LCFA) are produced through lipids hydrolysis and are often abundant in lipid-rich wastewaters. LCFA have a high energy potential, but their conversion to methane in continuous anaerobic systems is frequently hindered by the poor solubility and association to the sludge [1]. High LCFA concentrations may increase the lag phase period in $\beta$-oxidation process [2], which is partially due to transport limitation [3]. The accumulation of LCFA onto microbial cells creates a physical barrier and holds back the transfer of substrate and products [3]. Another limitation in LCFA conversion is often the low number of syntrophic bacteria in anaerobic sludges [4-6], which can limit the conversion rates of LCFA and/or intermediates. Efficient conversion of high LCFA loads in a continuous anaerobic reactor (organic loading rates (OLR) up to $21 \mathrm{~kg} \mathrm{~m}^{-3} \mathrm{~d}^{-1} ; 50 \%$ of COD as oleate) has been reported after a step-wise prolonged feeding [7]. It was suggested that the observed high rates are associated with the development

* Corresponding author. Laboratory of Microbiology, Wageningen University, Dreijenplein 10, Buildingnumber 316, 6703 HB Wageningen, The Netherlands. Tel.: +31 317 483107; fax: +31 317483829.

E-mail addresses: diana.sousa@wur.nl, dianasousa@deb.uminho.pt (D.Z. Sousa). 
of stable syntrophic community of LCFA-degrading bacteria and methanogenic archaea. Amendment of non-acclimated granular sludge with Syntrophomonas zehnderi, a LCFAdegrading bacterium, resulted in a 2-fold increase in the initial methane production rate from oleate batch conversion [8]. However, information on the long-term effect of bioaugmenting syntrophic bacteria in LCFA-fed reactors is lacking.

Here, we explore potential strategies to maintain and/or restore microbial activity after an LCFA shock. We studied long-term acclimation of anaerobic sludges to LCFA and investigated if longer acclimation times are beneficial to shorten the recovery of methanogenic activity after LCFA overload (LCFA overloaded sludge is used to designate sludge that has been withdrawn from a bioreactor continuously loaded with LCFA and containing biomass-associated substrate; accumulation of substrate onto the biomass normally precedes reactor failure episodes). In another experiment, LCFA overloaded sludges were bioaugmented with a coculture of S. zehnderi and Methanobacterium formicium to evaluate the potential of accelerating the recovery of methanogenic activity.

\section{Materials and methods}

\subsection{Methane production by LCFA-overloaded sludges}

\subsubsection{Source of LCFA-overloaded sludge}

A total of 54 sludge samples were collected from laboratoryscale anaerobic bioreactors and used for studying the effect of acclimation time on the lag phases of biomass-associated substrate conversion to methane, and its influence on the degradation of simple substrates $\left(\mathrm{H}_{2}-\mathrm{CO}_{2}\right.$, acetate, propionate and butyrate). Reactors had been operated with LCFA-based wastewaters containing oleate at a temperature of (308.15-310.15) K. Table 1 shows the conditions at the time of sampling and the contact time of the sludges with oleate. All the analyzed samples had biomass-associated substrate due to overload with oleate.

\subsubsection{Biodegradation of the biomass-associated substrate} Sludge samples described in Table 1 were washed and centrifuged twice with basal medium prepared as described by Alves et al. [9]. Vials $\left(25 \mathrm{~cm}^{3}\right)$ containing $12.5 \mathrm{~cm}^{3}$ of basal medium were inoculated with the anaerobic sludges to a final concentration of VS between $(3-5) \mathrm{kg} \cdot \mathrm{m}^{-3}$ and sealed with butyl rubber stoppers and aluminum caps. The headspace of the bottles was then washed with a mixture of $80 \%$ $\mathrm{N}_{2}$ and $20 \% \mathrm{CO}_{2}$ (total gas pressure in bottles' headspace was set at $100 \mathrm{kPa}$ ). Sludges were incubated without the addition of any substrate besides the substrate (mainly LCFA) associated to the sludge. Assays were performed in triplicate. Incubation was performed at $310.15 \mathrm{~K}$ while shaking $(2.5 \mathrm{~Hz})$. Biogas production was monitored with a pressure transducer and methane was quantified by gas chromatography (GC) [9]. Cumulative methane production data were fitted to the modified Gompertz equation (Section 2.4) to estimate lag phase time and maximum methane production in the assays. The maximum amount of methane produced (corresponding to the plateau of the methane production curves) was converted to its COD equivalent $\left(0.064 \mathrm{~kg} \mathrm{~mol}^{-1}\right)$ and was considered as an indirect measurement of the amount of biomass-associated substrate (as previously described by Pereira et al. [12]). Specific biomass-associated substrate was calculated by dividing the determined COD equivalent by the VS content in the vials at the end of the assays.

Table 1 - Conditions prevailing and exposure time to oleate of sludge sources used in this work.

\begin{tabular}{|c|c|c|c|c|c|}
\hline Reactor & Operation mode & Substrate & Co-substrate:Oleate (\%) & Time in contact with oleate (d) & References \\
\hline Fixed bed & Continuous & Skim milk + oleate & $50: 50$ & 103 & [9] \\
\hline Fixed bed & Continuous & Oleate & $0: 100$ & 214 & [9] \\
\hline Fixed bed & Continuous & Skim milk + oleate & $50: 50$ & 103 & [9] \\
\hline Fixed bed & Continuous & Oleate & $0: 100$ & 214 & [9] \\
\hline Fixed bed & Continuous & Skim milk + oleate & $50: 50$ & $20-55^{\mathrm{a}}$ & [10] \\
\hline Fixed bed & Continuous & Skim milk + oleate & $50: 50$ & $114-147^{b}$ & [10] \\
\hline EGSB & Continuous & Skim milk + oleate & $50: 50$ & 70 & [11] \\
\hline EGSB & Continuous & Skim milk + oleate & $50: 50$ & $70^{c}$ & [11] \\
\hline EGSB & Continuous & Oleate & $0: 100$ & $70-219^{d}$ & [11] \\
\hline EGSB & Continuous & Oleate & $0: 100$ & $70-219^{e}$ & [11] \\
\hline Column & Fed-batch & Skim Milk + oleate & $50: 50$ & 103 & [3] \\
\hline EGSB & Continuous & oleate & $0: 100$ & 178 & [3] \\
\hline UASB & Cycles & Skim Milk + oleate & $50: 50$ & $17-213^{\mathrm{f}}$ & [7] \\
\hline UASB & Continuous & Skim Milk + oleate & $50: 50$ & $473-665^{g}$ & [7] \\
\hline
\end{tabular}

EGSB - Expanded granular sludge bed; UASB - Up-flow anaerobic sludge blanket.

a 6 samples were collected in this period.

b 3 samples.

c 2 samples, one at the top and other at bottom of the reactor.

d 8 samples.

e 7 samples.

f 9 samples.

g 12 samples. 
2.1.3. Biodegradation of direct and indirect methanogenic substrates by LCFA overloaded sludges

The degradation of $\mathrm{H}_{2}-\mathrm{CO}_{2}$, acetate, propionate and butyrate by LCFA-overloaded samples was studied in batch assays according to the procedure described by Pereira et al. [12]. Briefly, sets of serum bottles were prepared as detailed in Section 2.1.2 and were individually supplemented with acetate $\left(30 \mathrm{~mol} \mathrm{~m}^{-3}\right)$, propionate $\left(30 \mathrm{~mol} \mathrm{~m}^{-3}\right)$, butyrate $\left(15 \mathrm{~mol} \mathrm{~m}^{-3}\right)$ or a mixture of $\mathrm{H}_{2}(80 \%)$ and $\mathrm{CO}_{2}(20 \%)$. Cumulative methane production was monitored, and the specific methane production values were calculated by dividing the initial slope of the cumulative methane production curves by the VS content of each vial at the end of the experiment. Background methane production due to residual substrate was measured in blank assays and discounted.

\subsection{Bioaugmentation of LCFA-overloaded sludge with a coculture of S. zehnderi and Methanobacterium formicicum}

\subsubsection{Bioaugmenting culture}

A coculture of S. zehnderi DSM $17840^{\mathrm{T}}$ and M. formicicum DSM $1535^{\mathrm{T}}$ was grown in bicarbonate-buffer mineral salt medium [13]. The methanogen was pre-grown in sealed bottles pressurized with a gas mixture $\left(80 \% \mathrm{H}_{2}\right.$ and $\left.20 \% \mathrm{CO}_{2}, 170 \mathrm{kPa}\right)$. After M. formicicum growth, the headspace of the bottles was flushed and pressurized under sterile conditions with $80 \% \mathrm{~N}_{2}$ and $20 \% \mathrm{CO}_{2}, 170 \mathrm{kPa}$ and further inoculated with a coculture of $S$. zehnderi and $M$. formicicum. The cultures were incubated at $310.15 \mathrm{~K}$, statically and in the dark and two successive additions of $0.5 \mathrm{~mol} \mathrm{~m}^{-3}$ sodium oleate ( $\geq 99 \%$, Fluka) were made. Then, the coculture was anaerobically centrifuged (15 $691 \mathrm{~m} \mathrm{~s}^{-2}, 15 \mathrm{~min}, 277.15 \mathrm{~K}$ ) and distributed in two bottles under $\mathrm{N}_{2}$ atmosphere; one of these bottles was heat treated two times ( $394.15 \mathrm{~K}, 40 \mathrm{~min}$ ) to inactivate the culture.

\subsubsection{Source of LCFA-overloaded sludge}

To obtain LCFA-overloaded sludge, a $2 \mathrm{dm}^{3}$ (working volume) plexiglas up-flow anaerobic column reactor was operated at (308.15-310.15) $\mathrm{K}$ in continuous mode for 82 days. Anaerobic granular sludge from a brewery wastewater treatment plant (SCC - Sociedade Central de Cervejas e Bebidas, S.A., Portugal, $38^{\circ} 52^{\prime} 58^{\prime \prime} \mathrm{N}, 9^{\circ} 3^{\prime} 25^{\prime \prime} \mathrm{W}$ ) was used as inoculum with a VS content of $16 \mathrm{~kg} \mathrm{~m}^{-3}$ and OLR between 2 and $6 \mathrm{~kg} \mathrm{~m}^{-3} \mathrm{~d}^{-1}$ were applied. Reactor operational parameters are shown in Table 2. Biogas flow rate and composition, total and soluble COD, volatile fatty acids (VFA) and VS were monitored during the experiment.
COD removal efficiency, methane production rate and methane yields decreased during the operation, and LCFA tended to accumulate in the bioreactor (Table 2, Supplementary Figure S1). Mixed liquor samples (sludge and liquid medium) with increasing LCFA concentrations were withdrawn from the reactor at three different operation times (days 26, 55 and 82) and used to perform batch bioaugmentation experiments (Section 2.2.3). These sludge samples were characterized in terms of LCFA, VFA and VS. The specific biomass-associated LCFA content was calculated as previously described in Section 2.1.2.

\subsubsection{Batch bioaugmentation experiments}

Mixed liquor samples $\left(35 \mathrm{~cm}^{3}\right)$ withdrawn from the reactor at days 26, 55 and 82 were transferred to $70 \mathrm{~cm}^{3}$ bottles under $80 \% \mathrm{~N}_{2}$ and $20 \% \mathrm{CO}_{2}$. S. zehnderi coculture was added to a final concentrations of $0.24 \mathrm{~kg} \mathrm{~m}^{-3}$. Inactivated coculture was used in non-bioaugmented controls. To guarantee uniform hydrogenotrophic activity in bioaugmented and non-bioaugmented assays, $M$. formicicum active culture was added to all the vials, including controls $\left(0.05 \mathrm{~m}^{3} \mathrm{~m}^{-3}\right)$. Vials were incubated at $310.15 \mathrm{~K}$ statically and in the dark. Methane concentration in the vials headspace was monitored throughout the experiments. Methane production data were converted to its COD equivalent $(\mathrm{kg})$ and divided by the vials biomass content $(\mathrm{kg})$. Specific cumulative methane production data were then fitted to the modified Gompertz equation (Section 2.4). VFA and LCFA were quantified at the beginning and at the end of the assays and expressed as equivalent COD.

\subsection{Analytical methods}

In the batch biodegradation assays methane was quantified by gas chromatography (Chrompack CP 9000) using a Porapak Q column and a flame ionization detector. $\mathrm{N}_{2}$ was used as carrier gas. Injection port, column and detector temperatures were $373.15 \mathrm{~K}, 308.15 \mathrm{~K}$ and $493.15 \mathrm{~K}$, respectively. In the continuous reactor (Section 2.2.2), biogas flow rate was measured using a Ritter MilliGascounter (Dr. Ing. Ritter Apparatebau GmbH, Bochum, Germany), and the methane content was analyzed using a Micro-GC CP-4900 (Varian Inc.) with a $10 \mathrm{~m}$ PPU column heated at $353.15 \mathrm{~K}$. A thermal conductivity detector $(328.15 \mathrm{~K})$ was used and helium (at $150 \mathrm{kPa}$ ) was the carrier gas. Injection port temperature was $383.15 \mathrm{~K}$. Total and volatile solids were determined according to Standard methods [14]. Total and soluble COD was determined using COD-cuvette test kits (Hach-Lange GmbH, Düsseldorf, Germany) and a DR 2800 spectrophotometer (Hach-Lange $\mathrm{GmbH}$ ). VFA were

\begin{tabular}{|c|c|c|c|c|c|c|}
\hline Period & Time (d) & OLR $\left(\mathrm{kg} \mathrm{m}^{-3} \mathrm{~d}^{-1}\right)$ & $\operatorname{HRT}(d)$ & Milk:oleate (\%) & COD removal efficiency (\%) & Methane yield (\%) ${ }^{a}$ \\
\hline I & $0-9$ & $2.3 \pm 1.1$ & $0.97 \pm 0.07$ & $50: 50$ & $98 \pm 1$ & $55 \pm 5$ \\
\hline \multirow[t]{3}{*}{ II } & $9-16$ & $4.1 \pm 0.5$ & $0.97 \pm 0.07$ & $50: 50$ & $99 \pm 0$ & $69 \pm 6$ \\
\hline & $16-37$ & $4.1 \pm 0.5$ & $0.97 \pm 0.07$ & $25: 75$ & $97 \pm 1$ & $68 \pm 15$ \\
\hline & $37-55$ & $4.1 \pm 0.5$ & $0.97 \pm 0.07$ & $0: 100$ & $65 \pm 8$ & $19 \pm 4$ \\
\hline III & $55-82$ & $5.7 \pm 0.9$ & $0.71 \pm 0.01$ & $0: 100$ & $64 \pm 7$ & $5 \pm 2$ \\
\hline
\end{tabular}


analyzed by high-performance liquid chromatography (HPLC; Jasco, Japan) using a Chrompack organic analysis column $(30 \times 6.5 \mathrm{~mm})$ with a mobile phase of $5 \mathrm{~mol} \mathrm{~m}^{-3} \mathrm{H}_{2} \mathrm{SO}_{4}$ at a flow rate of $0.01 \mathrm{~cm}^{3} \mathrm{~s}^{-1}$. The column temperature was set at $333.15 \mathrm{~K}$ and spectrophotometric detection was performed at $210 \mathrm{~nm}$. LCFA were analyzed as previously described by Neves et al. [15]. Esterification of free fatty acids was performed with propanol, in acid medium ( $3.5 \mathrm{~h}$ at $373.15 \mathrm{~K}$ ). Propyl esters were further extracted with dichloromethane and analyzed in a gas chromatograph (Varian 3800) equipped with a flame ionization detector and a eq.CP-Sil 52 CB $30 \mathrm{~m} \times 0.32 \mathrm{~mm} \times 0.25 \mu \mathrm{m}$ capillary column (Teknokroma, TRWAX). Helium was used as gas carrier at a flow rate of $0.02 \mathrm{~cm}^{3} \mathrm{~s}^{-1}$. Initial oven temperature was set at $323.15 \mathrm{~K}$ for $2 \mathrm{~min}$ and final temperature of $498.15 \mathrm{~K}$ was attained with a ramp rate $4.72 \mathrm{~K} \mathrm{~s}^{-1}$. Injector and detector temperatures were $493.15 \mathrm{~K}$ and $523.15 \mathrm{~K}$, respectively.

\subsection{Data analysis}

Experimental methane production data (expressed in COD) from batch incubations were fitted by the modified Gompertz equation (equation (1)) for estimation of the maximum methane production and lag phase time. For methane production curves and fitting results please check Figure S2 in the supplementary material.

$M(t)=P \cdot \exp \left[-\exp \left[\frac{R m \cdot e}{P}(\lambda-t)+1\right]\right]$

Where $M(t)=$ specific cumulative methane production $\left(\mathrm{kg} \cdot \mathrm{kg}^{-1}\right), \quad \mathrm{P}=$ maximum specific methane production $\left(\mathrm{kg} \cdot \mathrm{kg}^{-1}\right), R_{m}=$ specific methane production rate $\left(\mathrm{kg} \cdot \mathrm{kg}^{-1} \mathrm{~d}^{-1}\right)$, $e=2.7182818, \lambda=$ lag phase time (days). $R^{2}$ values and the standard error for each variables obtained were calculated.

Statistical significance of the differences observed in the maximum cumulative methane production achieved in bioaugmentation experiments was evaluated using single factor analysis of variances (ANOVA). Statistical significance was established at the $p<0.05$ level.

\section{Results and discussion}

\subsection{Effect of acclimation on methane production by LCFA-overloaded sludges}

LCFA-overloaded sludge samples containing different amounts of biomass-associated substrate were studied. Biomass-associated substrate was mainly composed of LCFA, but small amounts of other compounds were also present when a co-substrate (milk) was included in the feed $[7,12]$. It has been previously shown that specific amounts of biomassassociated LCFA higher than $1 \mathrm{~kg} \mathrm{~kg}^{-1}$ have a negative effect on the specific methane production rate (estimated by the initial slope of cumulative methane production curves) [12]. Here, we show that the biomass-associated LCFA also has an important effect on the lag phase preceding the onset of methane production, and interestingly this effect is dependent on the previous exposure time of the sludge to LCFA (Fig. 1).

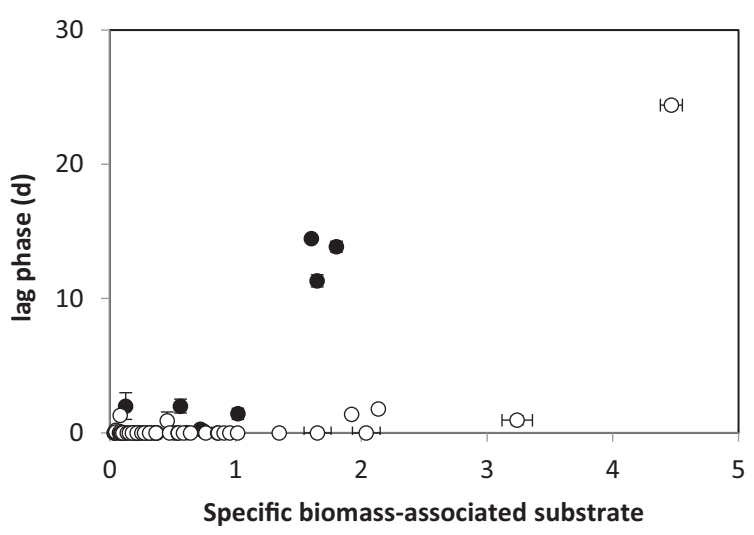

$\left(\mathrm{kg} \cdot \mathrm{kg}^{-1}\right)$

Fig. 1 - Lag phase in methane production from degradation of biomass-associated substrate from different sludge samples. Sludges exposed to LCFA for a period $<100$ days (๑). Sludges exposed to LCFA for a period $>100$ days $(\bigcirc)$.

For values of specific biomass-associated substrate up to $1 \mathrm{~kg} \mathrm{~kg} \mathrm{~kg}^{-1}$ almost no delay in methane production was observed, for all the tested sludges. However, a considerable increase in the lag phases was observed during the incubation of sludges with higher amounts of associated substrate, in particular non-acclimated sludges (exposed to LCFA for less than 100 days). Sludges that had been exposed to extended contact with LCFA (>100 days) performed better during the conversion of the biomass-associated substrate to methane. Sludge with specific substrate content as high as $(3.2 \pm 0.1)$ $\mathrm{kg} \cdot \mathrm{kg}^{-1}$ showed a lag phase of less than 1 day. Nevertheless, even acclimated biomass showed a high lag phase in methane production (i.e. $(24.4 \pm 0.3)$ days) when the specific biomassassociated substrate was about $4.5 \mathrm{~kg} \mathrm{~kg}^{-1}$. This means that sludges acclimatized for long periods (and with progressively increasing loads of oleate) recover their methanogenic activity rapidly when overloaded with LCFA, as long as the LCFA feed is interrupted. On the other hand, non-acclimatized sludges need more time to convert the biomass-associated substrate. Silvestre et al. [16] studied biomass adaptation over codigestion of sewage sludge and trapped grease waste and suggested also that a slow increase in grease waste could favor biomass acclimation, increasing LCFA degradation and reducing their latter inhibitory effect. During activity tests with oleate (approx. $0.25 \mathrm{~kg} \mathrm{~m}^{-3}$ ), a lag phase of 15 days was observed when using a sludge inoculum that was not acclimated to fat while no lag phases were observed with the adapted inoculum [16].

Usually, biomass-associated LCFA also have a negative effect on the specific methanogenic activity. Pereira et al. [17] observed a significant decrease of the specific methanogenic activity with $\mathrm{H}_{2}-\mathrm{CO}_{2}$, acetate, propionate and butyrate by LCFA overloaded sludges. In our work, specific methanogenic activity tests performed with the sludges exposed to extended contact with LCFA (>100 days), and containing associated substrate up to $5 \mathrm{~kg} \mathrm{~kg}^{-1}$, showed that biomass acclimation did not avoid the sharp decrease of specific methane production from $\mathrm{H}_{2}-\mathrm{CO}_{2}$, acetate, propionate and butyrate (Fig. 2). 

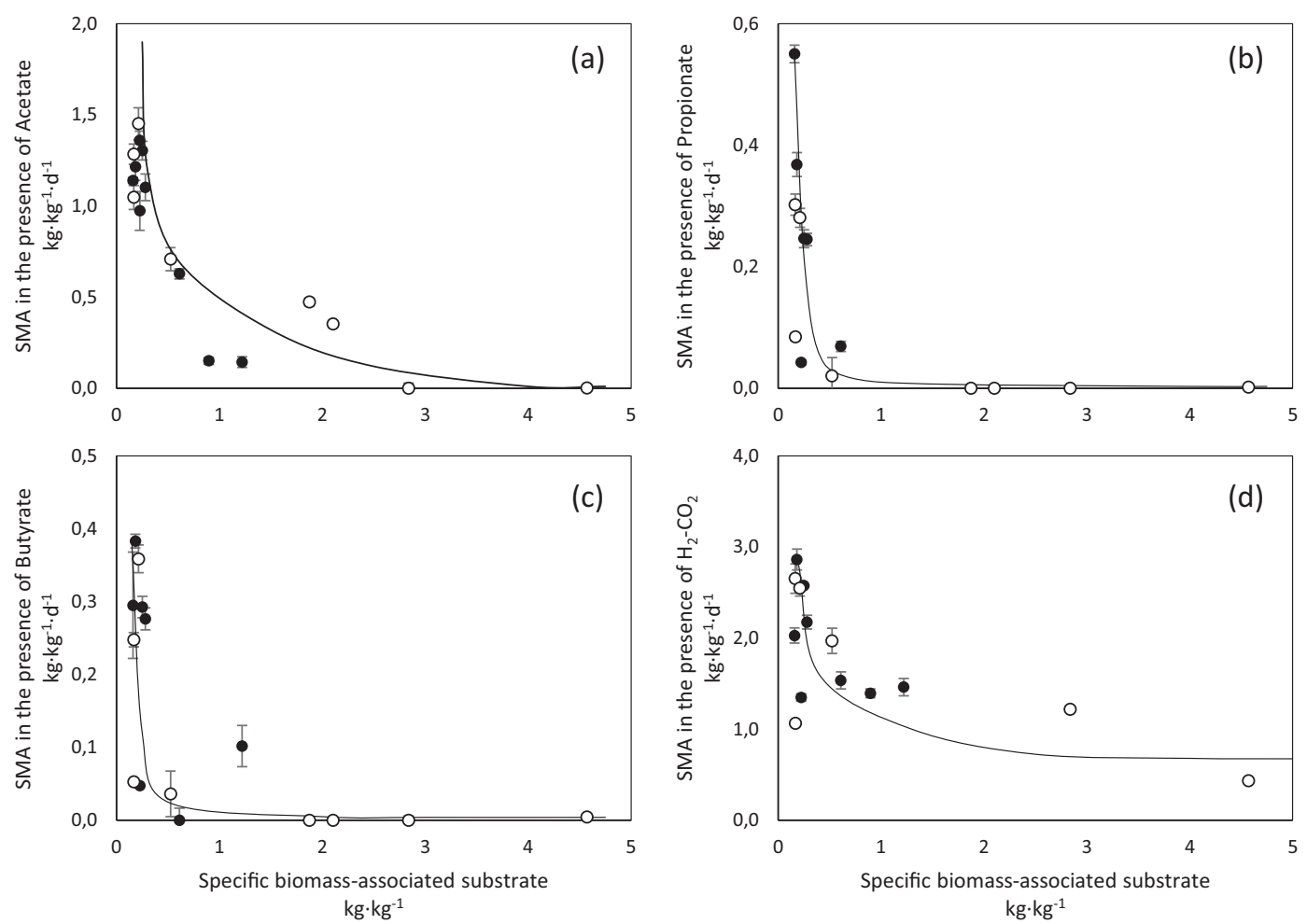

Fig. 2 - Specific methanogenic activity of the different sludge samples, containing different biomass-associated substrate contents, when in the presence of (a) acetate, (b) propionate, (c) butyrate and (d) $\mathrm{H}_{2}-\mathrm{CO}_{2}$ as substrates. Sludges exposed to LCFA for a period $<100$ days $(\Theta)$. Sludges exposed to LCFA for a period $>100$ days $(\bigcirc)$.

As previously reported by Pereira et al. [3,17], this effect is less severe in the presence of $\mathrm{H}_{2}-\mathrm{CO}_{2}$ and likely more related with mass transfer limitations imposed by LCFA accumulation than to metabolic inhibition. A decrease in hydrogenotrophic (with $\mathrm{H}_{2}-\mathrm{CO}_{2}$ ), acetoclastic (with acetate) and acetogenic (with butyrate) activities has also been observed in manure bioreactors after being exposed to oleate pulses [18]. However, activities were not irreversibly damaged and could be recovered after the degradation of the biomass-associated substrate $[3,18]$.

In continuous bioreactors these results have an important application, since the recovery of methanogenic activity, after an episode of LCFA overload, is possible if the feeding is interrupted and sufficient time is provided for degradation of the biomass-associated substrate. This recovery time, corresponding to the lag phases reported in this work, was shown to depend on long-term biomass acclimation, and on the amount of accumulated LCFA (Fig. 1).

\subsection{Bioaugmentation of LCFA-overloaded sludge with a coculture of S. zehnderi and M. formicicum}

LCFA-overloaded sludge with increasing LCFA concentrations were used to perform batch bioaugmentation experiments. LCFA and VFA concentrations were assessed the beginning and at the end of the experiments (Table 3). In all samples withdrawn from the reactor, palmitate accounted for (79-89) $\%$ of total LCFA; acetate was the main VFA detected in the samples collected on days 55 and 82. Specific methane production in bioaugmented vials and non-bioaugmented controls, as well as the different parameters calculated by fitting the modified Gompertz equation are shown in Table 3 (methane production curves in Figure S2).

Comparing the initial specific LCFA content and the maximum methane production obtained ( $\mathrm{P}$ in Table 3 ) the methane yield accounted only for (35-64) \% of the expected values (theoretical values of methane production from oleate and VFA are presented in Supplementary Table S1). The final values of LCFA content were around $2 \mathrm{~kg} \mathrm{~kg}^{-1}$, representing (59-65) \% of the initial LCFA concentration. Palmitate was the main LCFA present at the end of the assays, accounting for (81-94) \% of the total LCFA. VFA were also found in concentrations between 0.3 and $0.5 \mathrm{~kg} \mathrm{~kg}^{-1}$. The non-converted VFA and LCFA accounted for the difference between the initial COD and the COD recovered as methane.

No significant differences were observed in the maximum methane production neither in the lag phases, between the bioaugmented and non-bioaugmented assays (Table 3, Figure S2). Bioaugmentation success relies on the ability of the inoculated microorganisms to continue their activity in the new environment. Palatsi et al. [19] tested the addition of fresh manure to recover LCFA-inhibited bioreactors and observed an increase in maximum methane production rates. However, manure does not function solely as a seed of microorganisms and effects related to the presence of co-substrates or even the dilution of the bioreactor content cannot be disregarded. In LCFA-overloaded sludges, LCFA are largely associated with the biomass that is slowly obtaining the ability to degrade 
Table 3 - Specific VFA and LCFA concentrations at the start $\left(t_{0}\right)$ and at the end $\left(t_{f}\right)$ of the bioaugmentation assays and methane production parameters ( $P, \mathrm{Rm}$ and $\lambda$ ) obtained from methane production curves.

\begin{tabular}{|c|c|c|c|c|c|c|c|}
\hline & \multicolumn{2}{|c|}{ VFA $\left(\mathrm{kg} \mathrm{kg}^{-1}\right)$} & \multicolumn{2}{|c|}{ LCFA $\left(\mathrm{kg} \mathrm{kg}^{-1}\right)$} & \multirow[t]{2}{*}{$P\left(\mathrm{~kg} \mathrm{~kg}^{-1}\right)$} & \multirow[t]{2}{*}{$R_{m}\left(\mathrm{~kg} \mathrm{~kg}^{-1} \mathrm{~d}^{-1}\right)$} & \multirow[t]{2}{*}{$\lambda(\mathrm{d})$} \\
\hline & $t_{0}$ & $t_{f}$ & $t_{0}$ & $t_{f}$ & & & \\
\hline \multicolumn{8}{|c|}{ Bioaugmentation 1 (day 26) } \\
\hline Bioaug. & - & n.d. & $0.45 \pm 0.07$ & n.d. & $0.27 \pm 0.01$ & $0.07 \pm 0.01$ & 0 \\
\hline Non-bioaug. & - & n.d. & $0.45 \pm 0.07$ & n.d. & $0.28 \pm 0.01$ & $0.04 \pm 0.00$ & 0 \\
\hline \multicolumn{8}{|c|}{ Bioaugmentation 2 (day 55) } \\
\hline Bioaug. & 0.086 & n.d. & $0.69 \pm 0.1$ & n.d. & $0.39 \pm 0.01$ & $0.01 \pm 0.00$ & $1 \pm 1$ \\
\hline Non-bioaug. & 0.086 & n.d. & $0.69 \pm 0.1$ & n.d. & $0.36 \pm 0.01$ & $0.01 \pm 0.00$ & $3 \pm 1$ \\
\hline \multicolumn{8}{|c|}{ Bioaugmentation 3 (day 82) } \\
\hline Bioaug. & 0.272 & 1.89 & $3.2 \pm 0.61$ & 0.39 & $1.25 \pm 0.04$ & $0.04 \pm 0.00$ & $46 \pm 2$ \\
\hline Non-bioaug. & 0.272 & 2.08 & $3.2 \pm 0.61$ & 0.41 & $1.27 \pm 0.05$ & $0.04 \pm 0.00$ & $38 \pm 2$ \\
\hline
\end{tabular}

n.d. - not determined; $P$ (maximum specific methane production), $R_{m}$ (specific methane production rate), and $\lambda$ (lag phase time) were calculated by fitting the modified Gompertz equation to the experimental data; Person's correlation coefficient $(r) \geq 0.93$.

these compounds. Apparently, the bioaugmented methanogenic community used in this study does not have sufficient access to the insoluble substrate to enhance methanogenesis.

\section{Conclusions}

The amount of biomass-associated LCFA and long-term acclimation (>100 days of exposure) are essentials factors for avoiding the delay of methane production imposed by LCFA. Results point to the importance of the physical integrity of the syntrophic communities with the insoluble substrate and in situ development of highly-specialized microbial communities. From an application point of view, long-term sludge acclimation and avoidance of excessive LCFA accumulation are essential factors for the efficient conversion of LCFA to methane. Monitoring LCFA accumulation into the sludge is important for preventing serious overloading events. Ideally, specific biomass-associated substrate should be kept below $1 \mathrm{~kg} \mathrm{~kg}^{-1}$, although well-adapted sludges could still have a good performance with approximately three times this value.

\section{Acknowledgments}

The authors acknowledge the financial support by the European Regional Development Fund - ERDF, through the Operational Program Thematic Factors of Competitiveness - COMPETE, and by Portuguese funds, through the Portuguese Foundation for Science and Technology (FCT), in the frame of the project FCOMP-01-0124-FEDER-014784. FCT Strategic Project PEst-OE/ EQB/LA0023/2013 is also acknowledged. A.J. Cavaleiro thanks FCT for the post-doctoral fellowship ref. SFRH/BPD/75247/2010. A.J.M. Stams has received funding from the European Research Council under the European Union's Seventh Framework Programme (FP/2007-2013)/ERC Grant Agreement n. [323009].

\section{Appendix A. Supplementary data}

Supplementary data related to this article can be found at http://dx.doi.org/10.1016/j.biombioe.2014.05.012.

\section{R E F E R E N C E S}

[1] Alves MM, Pereira MA, Sousa DZ, Cavaleiro AJ, Picavet M, Smidt H, et al. Waste lipids to energy: how to optimize methane production from long-chain fatty acids (LCFA). Microb Biotechnol 2009;2(5):538-50.

[2] Kim S-H, Han S-K, Shin H-S. Two-phase anaerobic treatment system for fat-containing wastewater. J Chem Technol Biotechnol 2004;79:63-71.

[3] Pereira MA, Pires OC, Mota M, Alves MM. Anaerobic biodegradation of oleic and palmitic acids: evidence of mass transfer limitations caused by long chain fatty acid accumulation onto the anaerobic sludge. Biotechnol Bioeng 2005;92(1):15-23.

[4] Hansen KH, Ahring BK, Raskin L. Quantification of syntrophic fatty acid- $\beta$-oxidizing bacteria in a mesophilic biogas reactor by oligonucleotide probe hybridization. Appl Environ Microbiol 1999;65(11):4767-74.

[5] Menes RJ, Travers D. Detection of fatty acid beta-oxidizing syntrophic bacteria by fluorescence in situ hybridization. Water Sci Technol 2006;54(2):33-9.

[6] Stams AJM, Sousa DZ, Kleerebezem R, Plugge CM. Role of syntrophic microbial communities in high-rate methanogenic bioreactors. Water Sci Technol 2012;66(2):352-62.

[7] Cavaleiro AJ, Salvador AF, Alves JI, Alves MM. Continuous high rate anaerobic treatment of oleic acid based wastewater is possible after a step feeding start-up. Environ Sci Technol 2009;43(8):2931-6.

[8] Cavaleiro AJ, Sousa DZ, Alves MM. Methane production from oleate: assessing the bioaugmentation potential of Syntrophomonas zehnderi. Water Res 2010;44(17):4940-7.

[9] Alves MM, Vieira JA, Pereira RM, Pereira MA, Mota M. Effects of lipids and oleic acid on biomass development in anaerobic fixed bed reactors. Part I: biofilm growth and activity. Water Res 2001;35(1):255-63.

[10] Cavaleiro AJ, Alves MM, Mota M. Microbial and operation response of an anaerobic fixed bed digester to oleic acid overloads. Process Biochem 2001;37:387-94.

[11] Pereira MA, Pires OC, Mota M, Alves MM. Anaerobic degradation of oleic acid by suspended and granular sludge: identification of palmitic acid as a key intermediate. Water Sci Technol 2002;45(10):139-44.

[12] Pereira MA, Sousa DZ, Mota M, Alves MM. Mineralization of LCFA associated with anaerobic sludge: kinetics, enhancement of methanogenic activity, and effect of VFA. Biotechnol Bioeng 2004;88(4):502-11. 
[13] Stams AJM, van Dijk JB, Dijkema C, Plugge CM. Growth of syntrophic propionate-oxidizing bacteria with fumarate in the absence of methanogenic bacteria. Appl Environ Microbiol 1993;59(4):1114-9.

[14] APHA/AWWA/WPCF. In: Clesceri LS, Greenberg AE, Trussell RR, editors. Standard methods for the examination of water and wastewater. 17th ed. Washington, DC: American Public Health Association/ American Water Works Association/Water Environment Federation; 1989.

[15] Neves L, Pereira MA, Mota M, Alves MM. Detection and quantification of long chain fatty acids in liquid and solid samples and its relevance to understand anaerobic digestion of lipids. Bioresour Technol 2009;100(1):91-6.

[16] Silvestre G, Rodríguez-Abalde A, Fernández B, Flotats X, Bonmatí A. Biomass adaptation over anaerobic co-digestion of sewage sludge and trapped grease waste. Bioresour Technol 2011;102(13):6830-6.

[17] Pereira MA, Cavaleiro AJ, Mota M, Alves MM. Accumulation of long chain fatty acids onto anaerobic sludge under steady state and shock loading conditions: effect on acetogenic and methanogenic activity. Water Sci Technol 2003;48(6):33-40.

[18] Palatsi J, Illa J, Prenafeta-Boldú FX, Laureni M, Fernández B, Angelidaki I, et al. Long-chain fatty acids inhibition and adaptation process in anaerobic thermophilic digestion: batch tests, microbial community structure and mathematical modelling. Bioresour Technol 2010;101(7): 2243-51.

[19] Palatsi J, Laureni M, Andrés MV, Flotats X, Nielsen HB, Angelidaki I. Strategies for recovering inhibition caused by long chain fatty acids on anaerobic thermophilic biogas reactors. Bioresour Technol 2009;100(20):4588-96. 